\title{
TRUST AND JOB INVOLVEMENT AS DETERMINANT OF KNOWLEDGE SHARING BEHAVIOR
}

\author{
Benita Rachmania \\ STIE Malangkucecwara, Malang, Indonesia \\ benitarachmania@stie-mce.ac.id \\ Hanif Mauludin \\ STIE Malangkucecwara, Malang, Indonesia \\ hanif@stie-mce.ac.id
}

\begin{abstract}
Knowledge sharing has become an important part of organizations in increasing their competitiveness. However, the antecedent variable for the practice of knowledge sharing behavior is still very limited. This study aims to examine the influence of trust among organizational members and job involvement on the intensity of knowledge sharing behavior. The study involved 250 lecturers from various universities in the city of Malang, Indonesia. The research data were collected through a questionnaire and processed using SEM Partial Least Square. The results showed that trust among organizational members influenced job involvement and knowledge sharing practices. Furthermore, job involvement is proven to be a variable that mediates the effect of trust on knowledge sharing behavior.

Keywords: knowledge sharing behavior, trust, job involvement, knowledge management, competitive advantage DOI: https://doi.org/10.24818/beman/2021.11.1-07
\end{abstract}

\section{INTRODUCTION}

One of the most important aspect in an organization is the quality of their human capital resource. There are two main reasons which are human resource becomes the main subject of policy implementation and are the operational drivers of an organization. Henceforth, to be able to compete within the industry, an organization must be able to maintain the quality of their human resource. This research focuses on educational enterprises particularly on universities as an end point of formal education. Universities try to enhance the capabilities of human capital such as lecturers through curriculum development, education level, teaching, research, and community services. One means of enhancing several of these capabilities are through interactions between co-workers especially in a university environment which needs constant 
update on new knowledge. Knowledge sharing is one of the most effective methods in exchanging new information between co-workers because it explores the uniqueness of each organization and can indicate that an organization has competitive advantage compared to others (Lin, 2007). Therefore, this research expounds knowledge sharing culture within an organization.

In practice, knowledge sharing between lecturers has been proven to make information easier to be disseminated and preserve "stock of knowledge" within the university. However, most organizations have a hard time implementing and maintaining the culture of sharing between co-workers (Lam et al. 2010). In being able to share knowledge between co-workers, requires an individual to have the intention in being open to share information rather than keeping information for themselves Chow and Chan (2008) further emphasizes that openness becomes the key in being able to build a knowledge sharing culture.

Openness can be hard to be obtained because generally knowledge is perceived as a valued asset and sharing it would be against each individual natural tendency to hide anything of value. This could also indicate that there may be unhealthy interactions happening between co-workers (Hsu and Lin. 2008). Henceforth, universities be able to build the behavioral culture of knowledge sharing within the organization. To do otherwise would eventually create long-term sustainability problems due to absence of healthy interactions (Lin, 2007).

The key element to be able to build this kind of culture is by implementing a strong base of strategy which could improve the organizational culture and able to discover the uniqueness of each organization. In building this strategy, an organization must be able to bring together different characteristics of different individual. This can be achieved through building trust between the individuals. Trust is a crucial factor in every interaction which could also affect each commitment to share willingly. Trust is the remedy to ever lasting relationships and a reciprocal relationship. With trust someone can become confident, open, honest, willing to take risks, and becoming more comfortable in establishing relationships with others. The long-term effect does not only affect towards individuals but also effects on long-term trust for the organization. Long-term trust can eventually transform into an environment of transparency within an organization. It could also be the key to push boundaries towards innovative breakthrough and creative thinking. Furthermore, it could make employees more devoted towards the organization and eventually impact on a higher contribution towards the organization. There are other impacts which are the harmonization between systems and organizational; structures more effective strategy execution; and more effective and efficient use of organizational resources (Gounaris and Venetis, 2002). Thus, trust can also be reviewed as a valuable component to achieving the success of the organization / company goals. Another important factor besides trust towards knowledge sharing is job involvement. Job involvement means the depth of an employee engaged with their work. Knowledge sharing becomes more easier when an employee is more engaged with their work because of the high-level confidence they have. It is can 
also be the mediator between knowledge and trust. Therefore, this research explains whether job involvement can become the medium between trust and knowledge sharing. The theoretical purpose of this research is to explain the contribution of knowledge sharing behavior theory in constructing more competent human resources and bolstering organizational competitiveness. While the practical benefits of the study are expected to contribute to future in depth research, the application of this research findings may improve the competitiveness for higher education institutions.

\section{LITERATURE REVIEW}

\subsection{Empirical Review}

In practice, life within an organization requires individuals to be interconnected. Many management experts say that the existence of trust becomes crucial for everyone's interactions. Trust is a psychological area emphasizing on an individual acceptance based on their expectations of good behavior from others. In other words, trust can form a belief, willingness or behavioral tendency. Furthermore, it emerges from each community based on norms that are shared between them. Simply put, trust comes from an organizations culture and norm. Trust used within an organization is mutual trust based on shared values and norms of individuals or groups. This means that each individual or group will act as expected without the intention of being harmful against each other. Mutual trust between individuals can affect personal involvement, commitment, and success in an organization. Other benefits of mutual trust are rapid organizational growth; an increase of a climate for transparency; fostering innovation; creating harmony between systems and organizational structures; enhancing employee loyalty; and an efficient use of organizational resources (Kassim and Salaheldin, 2009). Therefore, trust can be categorized as an intangible asset that becomes very valuable to the organization. Robbins and Judge (2008) states that there are several key factors to mutual trust which are integrity, competence, consistency, loyalty, and 
uses all employee capacities and is designed to encourage commitment for the success of an organization. Job involvement can be seen from the attitude of a worker towards their work and their opinions about their work. For example, where an employee considers the job important for his selfesteem will likely have a high job involvement. Self-esteem in this sense can mean that If the work is considered meaningful and valuable both materially and psychologically for the worker, the worker will respect and will do his or her work as well as possible (Alam et al., 2016).

Knowledge is the result of reflection and experience of a person possessed by each individual or group. Knowledge is data and information combined with ability, intuition, experience, ideas, motivation from competent sources (Nonaka and Teece. 2001). Knowledge as information that changes something or someone, it happens when the information becomes the basis for action, or when the information enables someone or intuition to take different actions or actions that are more effective than previous actions. Furthermore, it can be used to solve problems and make decisions. Thus, it can be said that knowledge is information that has been analysed that can be used as a basis for action, problem solving, making decisions, and for taking a particular direction or strategy.

Knowledge sharing is defined as "a culture of social interaction, which involves the exchange of employee knowledge, experience, and skills through an entire department or organization" (Lin. 2007). In reality, it is difficult to create and maintain a culture of sharing knowledge because it is not easy to get people to be willing to share their knowledge with other colleagues (Lam and Lambermont, 2010). However, some may be more willing than others. Individual differences may be influenced by psychological or behavioral disposition.

According to Nonaka and Krogh (2009), knowledge sharing is a reciprocal process where individuals exchange knowledge (tacit and explicit knowledge) and jointly create new knowledge (solutions). One purpose of this definition consists of giving and gathering knowledge, which provides knowledge by communicating knowledge to others what is owned by someone's personal intellectual capital, and gathering knowledge refers to consulting with colleagues by sharing information or intellectual capital they have. Knowledge sharing consists of distributed understanding relating to providing workers access to relevant information and building and using knowledge networks through organizations (Hogel et al., 2003). Several studies have demonstrated that knowledge sharing is very important because it enables organizations to improve innovation performance and reduce excessive learning effort (Calantone et. al., 2002).

Hooff and Ridder (2004) stated that there are two important aspects in knowledge sharing which are knowledge donating and knowledge collecting. Knowledge sharing comes from internal sources of the organization where competitors cannot be adapted or imitated. Thus, the ability to share knowledge is necessary on a short-term and long-term basis in the corporate world. As a form of applying this 
knowledge sharing capability, companies need to develop a knowledge-based organizational strategy. Knowledge based strategies are expected to be able to further explore the uniqueness of the organization. Organizations must be able to empower individuals in the organization, such as self-development in order to trigger more creative ideas and innovations in making new products / services, provide opportunities to advance their education, attend training/ seminars in the scope of work, participate in professional activities, provide better working environment, providing organizational rules and procedures that enable creative ideas and forming special divisions/departments that which allows knowledge sharing capabilities. The failure of organizations in applying this knowledge sharing ability is the inability of individuals and corporate organizations to learn to develop knowledge-based organizations. This learning disability can be detrimental to the company and competitiveness (Hoof \& Ridder, 2004).

There are two previous studies that have supported the objectives of this study, however through different lenses. Previous study concluded that job involvement, job satisfaction, organizational commitment and Organizational Citizenship Behavior as an independent variable influencing knowledge sharing behavior (Teh and Sun, 2012; Ho and Lin, 2012) This study reconfirms the extent of influence of job involvement on knowledge sharing behavior. The results of the study concluded that job involvement, job satisfaction, organizational commitment, and Organizational Citizenship Behavior as an independent variable influenced knowledge sharing behavior. This thesis reconfirms the extent of influence of job involvement on knowledge sharing behavior. Ho and Lin (2012) study is to examine the significance of trust in the workplace to knowledge sharing behavior. The study also explains the direct and indirect effects of trust in the workplace in enabling knowledge sharing behavior. The result of the study showed that trust has a significant effect on knowledge sharing behavior. However, previous research has its own limitations. The studies also emphasize the need for testing in reconfirming the extent to which the role of trust in the workplace and job involvement in contributing towards the behavior of sharing knowledge directly or indirectly.

\subsection{Hypotheses Development}

Due to the limitations of previous studies, this research will examine the extent of the role of work involvement in mediating the influence of trust on knowledge sharing behavior. The role of job involvement as a mediating variable is based on logical and empirical reasoning that trust in the workplace can indeed be a direct or indirect influence towards knowledge sharing behavior. The below shows a proposed model hypothesis in which this study will focus on. 


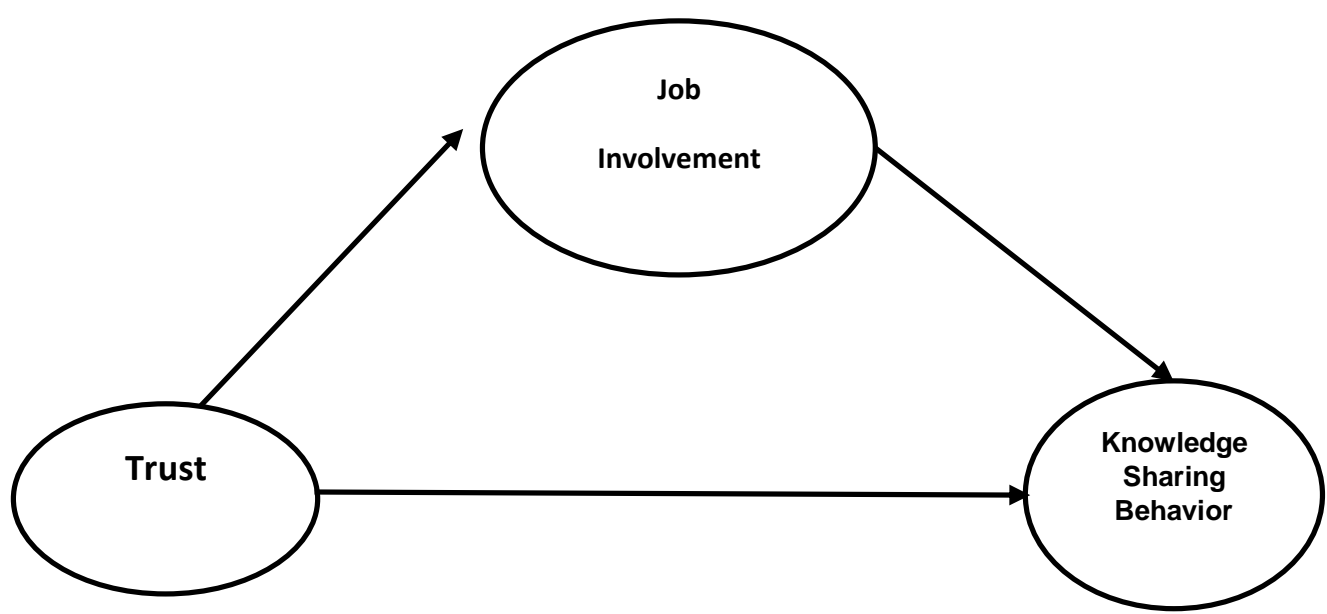

FIGURE. 1 CONCEPTUAL MODEL: TRUST AND JOB INVOLVEMENT AS DETERMINANT OF KNOWLEDGE SHARING BEHAVIOR

Source: Researcher's Conceptual Model

In the research model the trust factor becomes the main exogenous construct. The focus of this research has a means to increase engagement and habitual behavior of sharing knowledge within an organization. Without trust in an organization, harmony and openness to share knowledge will not be able to run effectively. Furthermore, with high job involvement, the intensity of information exchange will increase. This can lead to knowledge sharing behavior. Based on the conceptual model developed, the research hypothesis is formulated as follows:

Previous research has noted that trust can be used as a predictor of productive behavior. Trust has two dimensions, namely credibility on tasks that can be carried out effectively and reliably based on confidence in partner expertise. Then the second dimension is benevolence which is a belief in the partner's intentions and motivation which will later provide mutual benefits which explains that the initiation of a relationship with partners is based on trust. With high trust will certainly affect personal involvement, commitment, and success in an organization.

H1. There is a positive and significant effect between trust and job involvement.

Trust is a dynamic behavior that occurs intrinsically in a natural state, where trust is a matter of mental problems based on one's situation and social context. Trust does not only depend on experience but also involves relationships with mental processes where there are cognitive and affective aspects in it. This explains that trust does not only depend on experience as information obtained from time to time, but also involves emotional responses and feelings associated with these experiences. To be able to trust, one will expect a sense of responsibility, trusting that they will behave in ways that can be trusted. With trust, someone will hope that the person who wants him to believe will understand his expectations and know 
how to overcome his limitations, because it is the most essential thing from belief is openness. this is a strong asset so that knowledge sharing behavior will occur naturally in the organization.

$H 2$. There is a positive and significant influence between trust on knowledge sharing behaviour.

Work involvement in work activities is important to note. employees with high work involvement make them willing and happy to work together, both with their leadership and with their colleagues. The high level of job involvement also encourages employees to contribute ideas for job advancement, who are happy to share experiences and knowledge. Job involvement will increase one's participation in carrying out specific tasks and those relating to other employees. Employees who have high work involvement will tend to increase cooperation with others so that there is a process of exchange and sharing of knowledge.

H3. There is a positive and significant influence between job involvement on knowledge sharing behavior

\section{METHODOLOGY}

\subsection{The Study Context, Sampling and Data Collection}

The purpose of this study in outline is to examine the effect of several independent variables on the dependent variable both direct and indirect effects. This is intended to test some of the hypotheses that have been proposed above. Therefore, this type of research that is in accordance with the objectives and hypotheses is causality research. This research describes the causal relationships between several situations drawn in the model above and will draw conclusions based on the findings of this research. The sample are lecturers form various university in Malang city Indonesia. The sampling technique used is purposive sampling. These samples have teaching experience of at least 2 subject courses in each field of study and more than five years' experience. We have 250 lecturers as samples. The method of collecting data uses primary data in the form of a questionnaire sent to the respondents. These questionnaires are made in accordance with research indicators from each variable. The response options provided in this study's questionnaire followed the 5-point Likert type scale (5 = strongly agree, 1 = strongly disagree)

\subsection{Variables and measurement}

Trust is measured by 5 indicators refer to Hsu and Lin (2008) includes amount of trusted co-workers, information from co-workers, openness between partners, a sense of togetherness in responding to problems and the building of a spirit of brotherhood.

Job involvement measured by 4 indicators refer to Teh \& Sun (2012) includes: developing self-capability, the degree of interest of the lecturer in his work, the level of work engagement and find solutions or innovations for their work. 
Knowledge Sharing Behavior is measured by 4 indicators refer to Chiang, Han and Chuang (2011) include: sharing knowledge with colleagues, sharing experiences with co-workers, showing effectiveness at work and willingness to discuss with colleagues.

\subsection{Data analysis}

Data analysis was made by using Partial Least Square (PLS) with SmartPLS software. PLS is a variancebased structural equation analysis (SEM) to test the validity and reliability and test this research model.

\section{RESULTS AND DISCUSSION}

\subsection{Validity and Reliability test}

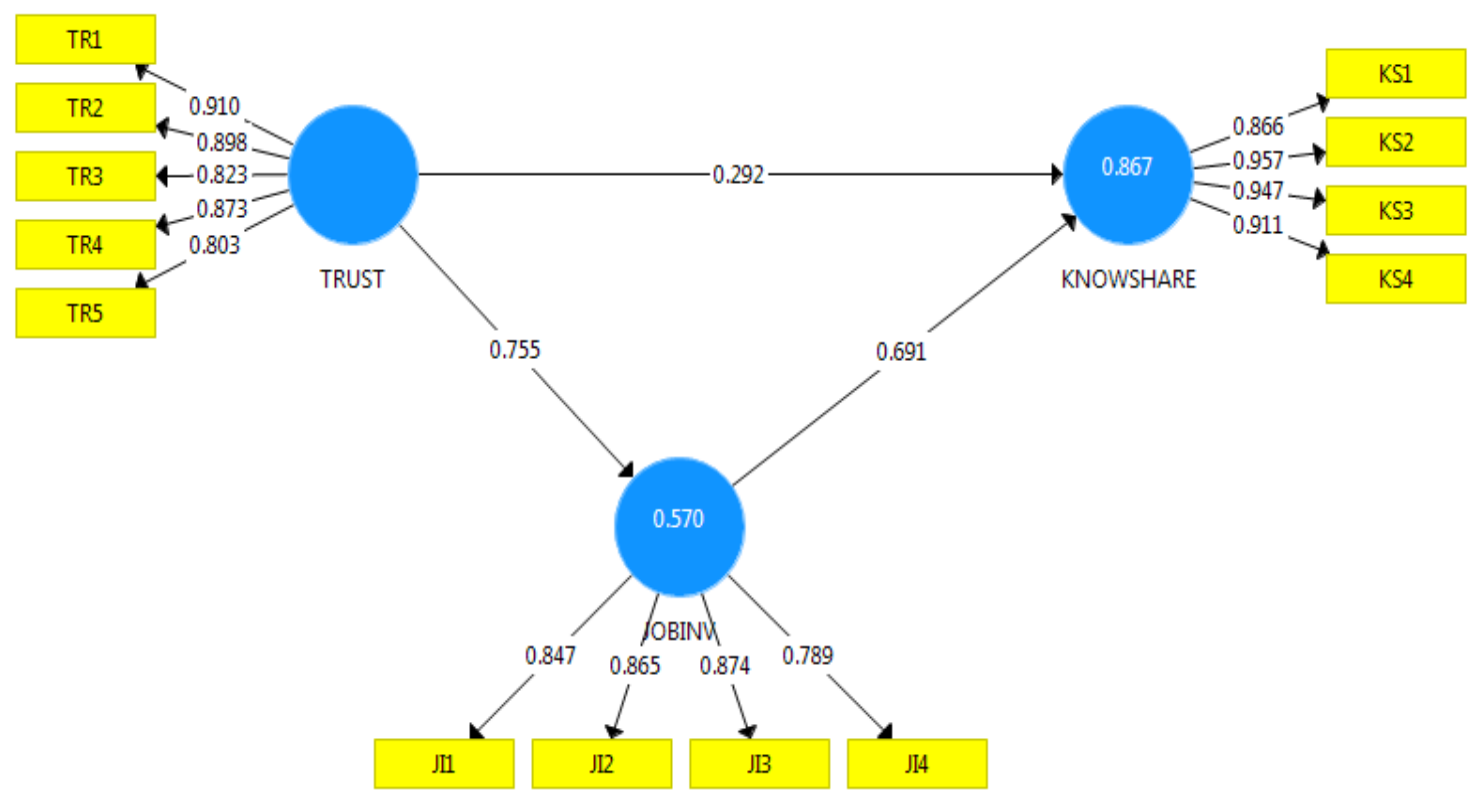

FIGURE 2. OUTER LOADING

Source: Smartpls output

Based on Figure 2, Outer loading on each indicator has a value above 0.6. Thus, it can be concluded that the indicators are sufficient in measuring the construct. Further testing of the construct validity can also be seen from the cross-loading values presented in Figure 2. Construct Reliability (Cronbach alpha measures the reliability of constructs or latent variables) the value must be above 0.70 which is considered reliable. However, for exploratory research, a moderate reliability of $0.5-0.6$ is sufficient to justify the results of the study. The reliability test with SmartpLs showed that the Cronbach alpha value of each variable was more than 0.70 . 


\subsection{Hypothesis test}

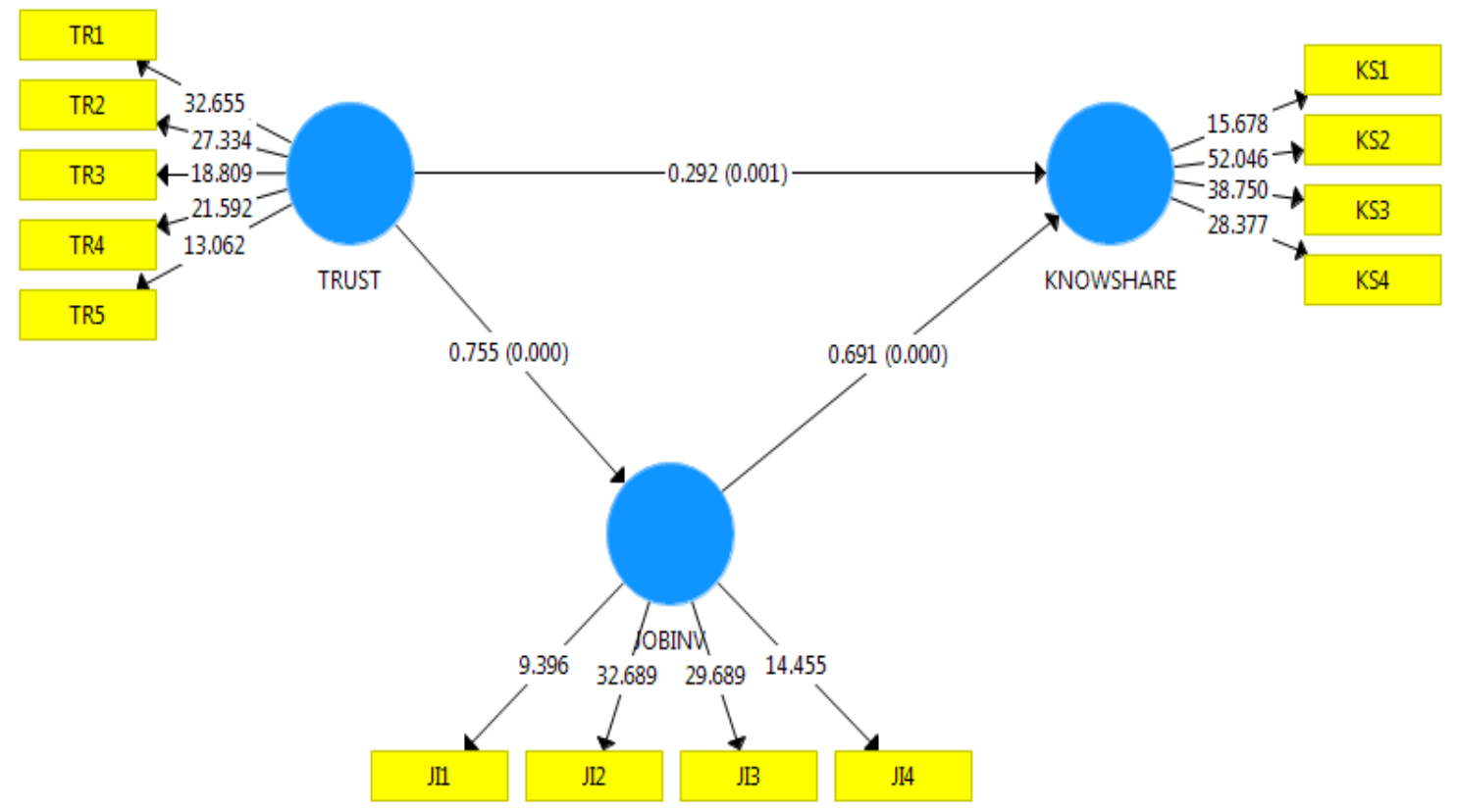

FIGURE 3. PATH COEFFICIENT

Source: Smartpls output

As mentioned, this study shows the extent of influence of trust in knowledge sharing behavior, both directly and indirectly towards job involvement as an intervening variable. The Figure 3 below shows path coefficients in the research model.

Based on the Figure 3 can be concluded that all hypotheses can be accepted. There is a positive and significant influence between trust on knowledge sharing behavior with a path coefficient of $0.292(0.001)$. Furthermore, there is also a positive and significant effect between trust on Job involvement with a path coefficient of $0.755(0.000)$. Lastly, there is a positive influence between job involvement on knowledge sharing behavior with a path coefficient of 0.691 .

By comparing the magnitude of the path coefficient of direct and indirect influence of trust on knowledge sharing behavior can be obtained by the effect of indirect influence which is shown by coefficient of 0.521 $(0.691 \times 0.755)$. this result is greater than 0.292 . Thus, job involvement is founded to be the mediating variable.

The predictive ability between trust and job involvement on knowledge sharing behaviour is fairly strong with $\mathrm{R}$ square about 0.867 . On the other hand, the predictive ability of trust on job involvement is moderate (0.57). However, both results show the ability to explain the data. 


\subsection{Discussion}

\subsubsection{The influence of trust on job involvement and knowledge sharing behavior}

The results of this study support Teh and Sun (2012) theory which states that trust is important for a relationship because in it there is an opportunity to carry out cooperative activities, knowledge, autonomy, self-respect, and other moral values. Being constantly involved in the job performed requires cooperative activities mentioned above which certainly requires cooperation of all parties involved. Thus, trust is founded to be one of the keys to a job's involvement process. Furthermore, the results of this study confirm the appropriateness of Ho and Lin (2012) study which argues that when employees have high trust in their organizations, they will build a degree of care about the future and success of the company. They also would be aware of their role within the organization and maximize their capacity within their role. With a lack of trust, little commitment will be built and eventually it will affect their behavior towards their work partners.

Trust that is built between members of the organization will develop the magnitude and intensity of job involvement in the organization. This means that an employee's job involvement occurs because of the trust between individual employees (Impersonal Trust). Therefore, it would create an atmosphere of determination in intensively being involved in both formal and informal organizational activities.

Trust has five important aspects in it, which underlie a personal relationship. The first aspect is openness where co-worker can share information, ideas, thoughts, and feelings. Second, sharing is the second aspect which shows an offer emotional assistance, material assistance and other resources. The third aspect is acceptance which shows there is full communicative appreciation towards their co-workers. Fourth, is support which means being able to communicate with other people and acknowledging other people's capability. Lastly, is cooperative intention which indicates the expectation that someone can cooperate and the ability of each personnel to work together to achieve the fulfilment of goals. Henceforth, when an organization can establish five aspects within each personnel, it will improve the culture of knowledge sharing behaviour and inevitably improve the performance of a company.

\subsubsection{The effect of job involvement on knowledge sharing behavior}

The results of this study can support the theory put forward by Robbins and Judge (2008); Ho and Lin (2012) that job involvement is part of the work attitude. In effect, it will have a direct impact on increasing employee productivity. In addition, job involvement has consequences in the form of work achievements, which can include willingness to share experiences and effective methods of doing a certain job task. Therefore, by becoming more involved in their work, members of the organization are expected to be able to produce better performance. Based on trust, individuals are able to increase their job involvement. In consequence, there is room for learning well with one another through knowledge sharing at workplace 


\section{CONCLUSIONS AND SUGGESTIONS}

Trust has a significant effect on job involvement. The results of this study support research conducted by Ho and Lin (2012) who found that Trust has a positive and significant effect on job involvement. Trust has a significant effect on Knowledge Sharing Behavior. The results of this study support research conducted by Ho and Lin (2012) who found that Trust has a positive and significant effect on knowledge sharing behavior. Job involvement also significantly influences knowledge sharing behavior. The results of this study support the research conducted by Teh and Sun (2012) who found that work involvement had a positive and significant effect on knowledge sharing behavior. Job involvement is also found to be an intervening variable that decorates the relationship between trust and knowledge sharing behavior.

Finally, we suggestions that knowledge sharing program is a forum for information exchange related to the profession between lecturers to communicate and discuss new things. The program is intended to transfer information and explore aspirations between lecturers regarding their scientific discipline, so that they directly can share their experiences and knowledge. This program can also strengthen relationships between lecturers to increase trust between lecturers, involvement in doing work and foster high commitment to the organization. For further researchers it is recommended to add to the study by testing the extent of leadership role and teamwork culture in interacting with variables that have been tested in this thesis model.

\section{REFERENCES}

Alam, R., Bima, M. J., Jusmin, A., and Said, S. (2016). Specific Determinants of Work Motivation, Competence, Organizational Climate, Job Satisfaction and Individual Performance: A Study among Lecturers. Journal of Business and Management Sciences. 4(3): 53-59

Calantone, R., Cavusgil, S. and Zhao, Y. (2002). Learning orientation, firm innovation capability, and firm performance. Industrial Marketing Management, 31(6): 515-524.

Chiang, H., Han, T. and Chuang, J. (2011). The relationship between high-commitment HRM and knowledge-sharing behavior and its mediators. International Journal of Manpower, 32(5/6): 604-622.

Chow, W.S. and Chan, L.S. (2008), "Social network, social trust and shared goals in organizational knowledge sharing", Information \& Management, 45(7): 458-65.

Gounaris, S. and Venetis, K. (2002). Trust in industrial service relationships: behavioral consequences, antecedents and the moderating effect of the duration of the relationship, Journal of Services Marketing, 16(7): 636-655

Ho, L., Kuo, T. and Lin, B. (2012). How social identification and trust influence organizational online knowledge sharing. Internet Research, 22(1): 4-28.

Hogel, M., Parboteeah, K.P. and Munson, C.L. (2003). Team-level antecedents of individuals' knowledge networks. Decision Sciences, 34(4): 741-70. 
Hooff, B \& Ridder, Jan. (2004). Knowledge sharing in context: The influence of organizational commitment, communication climate and $\mathrm{CMC}$ use on knowledge sharing. J. Knowledge Management. 8(1): 117-130

Hsu, C.L. and Lin, J.C.C. (2008). Acceptance of blog usage: the roles of technology acceptance,social influence and knowledge sharing motivation. Information \& Management, 45(1): 65-74.

Kassim, N and Salaheldin, S. 2009. Investigating the complex drivers of loyalty in e-commerce settings. Measuring Business Excellence. 13(10): 56-71.

Lam, A., and Lambermont-Ford, J.P. (2010). Knowledge Sharing in Organisational Contexts: A Motivation-Based Perspective. Journal of Knowledge Management. 14(1)

Lin, C.P. (2007). To share or not to share: modeling knowledge sharing using exchange ideology as a moderator. Personnel Review, 36(3): 457-475

Nonaka, I. and Krogh, V, G. (2009). Tacit knowledge and knowledge conversion: controversy and advancement in organizational knowledge creation theory. Organization Science. 20(3): 635-652.

Nonaka, I., and Teece, D. (2001). Managing Industrial Knowledge. London: SAGE.

Robbins, S. P., and Judge, T. (2008). Organizational behavior. Upper Saddle River, N.J: Pearson/Prentice Hall.

Teh, P., and Sun, H. (2012). Knowledge sharing, job attitudes and organizational citizenship behaviour. Industrial Management \& Data Systems. 112(1): 64-82. 